Print ISSN: 2288-4637 / Online ISSN 2288-4645

doi:10.13106/jafeb.2020.vol7.no10.909

\title{
Factors Influencing Life-Long Learning: An Empirical Study of Young People in Vietnam
}

\author{
Lan NGUYEN ${ }^{1}$, Phong $\mathrm{LUU}^{2}$, $\mathrm{Ha} \mathrm{HO}^{3}$
}

Received: August 01, 2020 Revised: September 06, 2020 Accepted: September 10, 2020

\begin{abstract}
This study, not only investigates the important role of lifelong learning in shaping young people's knowledge and in maximizing their potential, but also aims to shed light on the influencing factors of lifelong learning of young people in Vietnam. The author applied STATA and SPSS to analyze quantitative data collected from questionnaires with 332 respondents aged between 19 years old and 24 years old. Based on a holistic review of literature, this study concludes that four driver factors affect young people's lifelong learning ability, comprising: organizational culture, motivation, human resource development, and domestic private type of enterprise. The results emphasize the positivity of organizational culture, human resource development, and the nature of work, especially organizational culture and human resource development, which are dominant reasons for young people to maintain lifelong learning. The relationship between demographics and lifelong learning was tested and it indicated that male has a stronger interest in learning than female. The result of the study also shows the impact of different types of business sectors on employees' learning intentions. It points out that the domestic private type of enterprise is the most effective factor that has a positive relationship with the lifelong learning of the individual.
\end{abstract}

Keywords: Lifelong Learning, Educational Outcomes, Working Environment, Human Resources

JEL Classification Code: A23, C12, C31, C83

\section{Introduction}

In 2019, a great downturn occurred in the rate of unemployment from which there were approximately 10.9 million people who did not have jobs and represented only $3.1 \%$ of the total population if considering sub-region as South-east Asia and the Pacific (International Labour Organization, 2020). More specific, the Vietnamese unemployment rate extracted from the General Statistics Office of Viet Nam declined continuously and surprisingly

${ }^{1}$ First Author and Corresponding Author. School of Accounting and Auditing, Van Lang University, Ho Chi Minh City, Vietnam [Postal Address: 45 Nguyen Khac Nhu, Co Giang, District 1, Ho Chi Minh City, 700000, Vietnam] Email: ntnlan@vanlanguni.edu.vn.

${ }^{2}$ School of International Business Administration, Foreign Trade University, Vietnam. Email: luunhatphong0512@gmail.com

${ }^{3}$ Faculty of political theory, Banking University, Vietnam.

Email: hovietha85@gmail.com

(c) Copyright: The Author(s)

This is an Open Access article distributed under the terms of the Creative Commons Attribution Non-Commercial License (https://creativecommons.org/licenses/by-nc/4.0/) which permits unrestricted non-commercial use, distribution, and reproduction in any medium, provided the original work is properly cited. from $2.33 \%$ to $2.19 \%$ from 2015 to 2018 , it was much lower than the overall number in both sub-region and the ASIA (General Statistics Office of Viet Nam, 2015 - 2018). Therefore, it is necessary to investigate the reason behind these positive and remarkable figures.

Moreover, numerous studies have been examined internationally from diversified perspectives around lifelong learning such as workplace learning in small- and mediumsized enterprises in the UK (Ahlgren \& Engel, 2011), assessment scale for lifelong learning in the university context in Canada (Kirby et al., 2010), or lifelong learning competence scales for teachers from secondary schools in Turkey (Uzunboylu \& Hürsen, 2011). Indeed, lifelong learning is believed to be a mechanism, not only for enhancing personal potential, but also for motivating them to achieve a better version of themselves.

However, there are limitations that research could not cover for every part of the world, especially Vietnam ( Vu, 2020). Also, research is not close at the current time even though the business is changing day by day; specifically, the number of young Vietnamese workers who account for $12.7 \%$ of the total population in working age is bursting (General Statistics Office of Viet Nam, 2018). We aim to find 
out the hidden factors that can boost the learning capability of the youth in Vietnam in recent years as well as contribute insights to the literature of lifelong learning.

\section{Literature Review}

\subsection{Theories Related to Lifelong Learning}

As the economy throughout Southeast Asia is growing rapidly, Vietnam and other countries are becoming more and more market-integrated and foreign-affair oriented. The emerging economy also leads to the increasing income of each individual within the region (Samphantharak, 2019). However, it is significant that to achieve the high value of income, education, as well as learning, is in essence what should be improved because of their considerable influence on individual income (Park, 2017). Fortunately, the lifelong learning philosophy has spread out intending to educate and train individuals to deal with this revolution in development throughout countries in Southeast Asia (Uzunboylu \& Hürsen, 2011). Indeed, learning is an activity of experiencing and practicing, which leads to a relative change that stays permanent (Anderson, 1995; Altuwaijri \& Kalyanaraman, 2020). Therefore, lifelong learning is a comprehensive process covering the entire educational path of a human being from the first stage in pre-school into the last milestone in higher education and working life (Demirel, 2009a; Rahman et al., 2020).

As lifelong learning happens throughout all stages within a human's lifespan, hence, it is undeniable that various modes of learning also appear when an individual implements his lifelong learning. The modes are formal learning, non-formal learning, and informal learning (Terziev, 2019; Uzunboylu \& Hürsen, 2011). Speaking from a European perspective, formal learning is normally established and implemented within a structured environment, and the participant can get a certificate when the course is finished. The other type as non-formal learning is less structured because it is based on the own plan of a learner. From that, the participants are expected to set their agendas, to be proactive in finding the opportunities for getting knowledge, generating plan as well as executing it, engaging in the courses. The last type of learning is informal learning. This learning does involve guides, but affects largely the activities and exposures of learners. So, it can be explained that informal learning is gradually enhanced from day-to-day activities of learners in the context of work, family, or the recreation of himself (European Centre for the Development of Vocational Training, 2014). Acknowledging these modes is important because they cover all the angles in forms of learning that appear in human life, from learning in an educational institution, or learning in the working environment, to learning by the individual himself.

Therefore, many studies have been conducted to discover more aspects of lifelong learning. Demirel (2009) aims to prove the benefit of lifelong learning in establishing and enhancing the potentiality of an individual at his maximum capability. Laal (2011) has suggested integrating lifelong learning into information and communication technology within the current trend of digital transformation. The call for applying technology to lifelong learning is also regarded as necessary in this new era (Sharples, 2000). Moreover, in the context of Vietnam, lifelong learning was proved to be needed and have a positive relationship to pursue a job in the long term (Nguyen, 2015). Also, non-formal learning provides a boost in practical knowledge for Vietnamese people in their career paths (Nguyen, 2010). Therefore, it is undeniable that the factors influencing both types of lifelong learning should be investigated with the final aim to seek continuous improvement.

\subsection{Hypotheses}

This study recognizes two groups of factors. As learning throughout the life cycles is regarding developing human self-realization, it should be related to the human characteristics to smooth the process of self-realization (Selvi, 2009). Therefore, the first group derived from the individual factors, which are: gender, age, qualification, and motivation. The second group consists of the surrounding environment, which includes five factors: the individual's position at work, type of business sector, organization's culture, human resource development within the company, and the work itself (Sambrook \& Stewart, 2000).

\section{H1: There is a positive connection between gender and lifelong learning.}

Chłoń-Domińczak (2013) has shown that in the context of Austria, Germany, Ireland, and Greece, men account for a higher percentage of participants in formal learning than women. By contrast, statistics show a higher percentage of women in non-formal education in most countries in the European Union, mostly in Denmark, Sweden, and Finland (Chłoń-Domińczak \& Lis, 2013). The matter of gender is also covered by analysis in Taiwan, which demonstrates a tight and robust connection between gender, lifelong learning by the mature community, and the level of socioeconomic (Chang et al., 2012).

\section{H2: Age influences an individual's lifelong learning capability.}

As the target audience of this study are fresh graduate students who have one to two years of work experience, it is quite important to put age into consideration. This period of life, which covers a group of people below 25 years old, is most relevant to the formal type of lifelong learning; it is also a time for activities in non-formal and informal 
learning (Laal, 2011). Moreover, from the study by ChłońDomińczak in 2013, the preferred opinion is to complete formal education at university before reaching 25 years old so that formal learning participation is playing a great influence by that age (Chłoń-Domińczak \& Lis, 2013).

\section{H3: Lifelong learning competency increases due to the upper level of qualification.}

Regarding the non-formal type of learning, from 1985, workers with low education have become more active in participating in training sessions. However, the growth in number is small, referring to the upsurge of the same training programs for professional workers (Fouarge et al., 2013). However, the rate is opposite between two qualification levels of an employee when both three modes of learning are examined (Sanders et al. 2014). The argument is also supported by statistics from 2007 to 2008 showing that the participation rate of academically-qualified employees was four times higher than the same rate of low-qualified employees (Stelt \& Voogd-Hamelink, 2009).

\section{H4: Individual motivation is positively influences an individual's lifelong learning}

Emotion, as well as motivation factors, includes two types, which are internal motivation and external motivation. However, internal encouragement is defined as the individual action to participate in activities mainly for his benefits. The reason is the perception of individuals regarding the activities as well as the learning, in this case, is appealing, fulfilling, and challenging (Collins \& Amabile, 1999). So, internal motivation could be determined as motivation for the improvement of an individual's lifelong education (Selvi, 2009).

\section{H5: Job position influences the lifelong learning of the individual.}

According to Chłoń-Domińczak (2013), the situation of the labor market is statistically significant within countries in the European Union. Rather than the increasing rate of unemployed groups in participating learning programs, the percentage of European youth in educational attendance who are simultaneously working and studying is noticeably high (Chłoń-Domińczak \& Lis, 2013). Therefore, this group could be investigated to see if it is significant enough to influence lifelong learning.

H6: The three types of business sectors have a positive effect on the lifelong learning ability of individuals.

School of librarians, archivists, and documentation specialists (EBAD) in 2003 had launched an online course for the three types of business sectors. The result of the first launch on employees from the private sector only came positive as per the feedback from directors. The second launch, which targets the three types, is also successful, with over $90 \%$ of learners who obtained their certificates. However, the result of the third phase, of course, was still positive, but the rate of successful completion is lower by 5\% (Sagna, 2005). As from the case from Sagna, information and communication technology would consequently affect the efficiency of lifelong learning. Thus, the types of business sectors are correlated to the lifelong learning ability of individuals.

\section{H7: Organizational culture is a positive driver of lifelong learning.}

It is important that the organization sets up and establishes its own culture for the benefit of both organizational development and the learning of employees working in that company. With the strategy focusing on this type of asset, the organization could have a huge growth potential with the sustained ability to deal with hostile competitors (Senge, 1990). Following the concept, the terms of the learningoriented organization is developed to be an initiative to achieve the goals of the learning enterprise. The internal company environment, as a result, could become a convenient place where the staff, as well as managers, have rooms to implement on-the-job and off-the-job training and apply modes of learning (Sambrook \& Stewart, 2000).

\section{H8: Human resource development has a positive influence on individual lifelong learning.}

To investigate organizational context, the demand for individual learning calls for the increment of purpose on human resource development, together with a transformation in the business and training function of members in the human resources development department. As a result, strategies and implementations raised from human resources development should affect the natural and lifelong learning of an individual staff (Stewart, 1992).

\section{H9: The characteristic of work is the constructive factor of lifelong learning of a human being.}

Sambrook 2000) investigated the test of learning influencing factors within four large companies in the United Kingdom. Subsequently, all employees admitted that they did not have time to invest in their learning activities because of the heavy workload. Moreover, when talking about factors from those companies that could improve their learning, the characteristics of work are also mentioned as the working environment when it encourages the employee to learn and communicate more regularly (Sambrook \& Stewart, 2000). 


\section{Data and Research Methodology}

\subsection{Data}

The study examines the lifelong learning situation in the workplace of Vietnamese young people who have recently graduated from their university or fourth-year students. The study was initiated and executed from $24^{\text {th }}$ May to $2^{\text {nd }}$ June 2020. The theoretical framework and research model is established and formulated in the first phase. The questionnaire is subsequently developed as the opening step of phase 2 . The official interview, as well as investigation, are then conducted. The data, which is collected from primary research methodology, is processed through the IBM SPSS and STATA software to be cleaned. Lastly, the results obtained from testing the research model will be the basis to conduct scientific discussions on new points that arose from the topic as well as to propose recommendations and further research directions.

\subsection{Empirical Models}

\subsubsection{Official Research Model}

In this study, STATA was utilized as a regression model for quantitative research. The regression model considers lifelong learning capability (LEARN) as the dependent variable. For the independent variables, there are a total of eleven factors classified into two groups. The private group contains gender, age, qualification, and motivation (MOV) of an individual. The other factors, including position of an individual, three types of business sector - state-owned enterprise (GOVE), domestic private company (PRI), and foreign investment enterprise (FORE) -, organization's culture (CUL), human resources development (HRD), and organization of work (WORK) fall into the outside group. To sum up, the regression model is described below:

Model: $\operatorname{LEARN}=\alpha+\beta 1 *$ Gender $+\beta 2 *$ Age $+\beta 3 *$ Qualification $+\beta 4 * \mathrm{GOVE}+\beta 5 * \mathrm{PRI}+\beta 6$

$* \mathrm{FORE}+\beta 7 *$ Position $+\beta 8 * \mathrm{CUL}+\beta 9$

$* \mathrm{MOV}+\beta 10 * \mathrm{HRD}+\beta 11 * \mathrm{WORK}+\mathrm{u}$

where: $\alpha, \beta 1, \beta 2, \beta 3, \beta 4, \beta 5, \beta 6, \beta 7, \beta 8, \beta 9, \beta 10, \beta 11$ are coefficients and "u" is an error.

\subsubsection{Questionnaires}

Survey questionnaires that follow the methodology of primary quantitative research are established based on elements devised by previous studies. Then, dimensions are described and coded to prepare data for analysis. Each independent variable that affects lifelong learning activities is measured on a 5-point Likert scale, from 1 (least effect) to 5 (greatest effect). Table 1 lists all the variables of the regression model.

\subsubsection{Data Collection}

The sample is gathered by sending questionnaires to people who are currently joining working activities. There are categorized into two groups: fourth-year students in economic universities and students who have obtained bachelor's degrees. There is nearly the same proportion of male and female respondents. However, there are unavoidable categories where one group is dominant in comparison to others. As regards age, 32\% of respondents are 22 years old and $29 \%$ are 24 years old. Bachelor's degree accounts for $94 \%$ of respondents in the qualification variable. In the business sector variable $78 \%$ of respondents are linked to domestic private enterprise. Finally, there are many more participants who are in junior staff position in their current companies.

\section{Results}

\subsection{Descriptive Analysis}

Firstly, Figure 1 shows the factors that directly affect the individual's lifelong learning categorized by work position. As it can be pointed out, motivation, organizational culture, and the nature of work are three factors that shape the lifelong learning ability. More specifically, the ratings express that motivation (MOV) is the highest and most significant factors that would provide a boost for lifelong learning. However, activities and programs for human resource development may not be suggested by the company's members as the other three factors. Still, the rate itself is good at around 3.5 points. It should be pointed out that the factor of human resource development decreases simultaneously with the increase in the position of employees. The same phenomenon also happens in the rate of organizational culture.

Figure 2 compares the factors affecting lifelong learning according to different business sectors. One special characteristic that should be noted is the preference of the motivation factor in promoting lifelong learning, including the case in Figure 4.9, which shows the rating within the business sector context. Otherwise, the overall rating by the business sector is relatively high, with the average rating that falls from 3.2 to upper. As the rating of the work in the stateowned enterprise is the lowest, it may suggest that repetitive tasks are assigned to the employees working in this type of enterprise. Therefore, the staff in state-owned enterprises would tend to consider organizational culture and individual motivation as the highest influence factors. 
Table 1: Lists of regression model's dependent and independent variables

\begin{tabular}{|c|c|c|c|c|}
\hline Variable & Meaning & Determined by & Source & Model \\
\hline \multirow{2}{*}{ Gender } & \multirow{2}{*}{ Gender } & Female & \multirow{2}{*}{ Selvi, 2009} & \\
\hline & & Male & & \\
\hline Age & Age & Age number & Selvi, 2009 & \\
\hline \multirow{2}{*}{ Qualification } & \multirow{2}{*}{ Qualification } & Bachelor's degree & \multirow{2}{*}{ Selvi, 2009} & \\
\hline & & Have not got a bachelor's degree & & \\
\hline GOVE & \multirow{3}{*}{ Business sector } & State-owned enterprise & \multirow{3}{*}{ Sagna, 2005} & \\
\hline PRI & & Domestic private enterprise & & \\
\hline FORE & & Foreign investment enterprise & & \\
\hline \multirow{5}{*}{ Position } & \multirow{5}{*}{ Position } & Intern & \multirow{5}{*}{$\begin{array}{c}\text { Chłoń- } \\
\text { Domińczak } \\
\text { and Lis, } 2013\end{array}$} & \\
\hline & & Junior staff & & \\
\hline & & Senior & & \\
\hline & & Manager & & \\
\hline & & Director & & \\
\hline \multirow{4}{*}{ CUL } & \multirow{4}{*}{$\begin{array}{l}\text { Organization's } \\
\text { Culture }\end{array}$} & Sharing of work experience & \multirow{4}{*}{$\begin{array}{l}\text { Sambrook and } \\
\text { Stewart, } 2000\end{array}$} & CUL1 \\
\hline & & Interpersonal communication & & CUL2 \\
\hline & & Learning-oriented culture & & CUL3 \\
\hline & & Difficult level in changing the existing culture & & CUL4 \\
\hline \multirow{5}{*}{ MOV } & \multirow{5}{*}{ Motivation } & Level of motivation & \multirow{5}{*}{$\begin{array}{l}\text { Sambrook and } \\
\text { Stewart, } 2000\end{array}$} & MOV1 \\
\hline & & Level of confidence & & MOV2 \\
\hline & & Level of responsibility on the employee & & MOV3 \\
\hline & & Personal initiative & & MOV4 \\
\hline & & Personal learning competency & & MOV5 \\
\hline \multirow{5}{*}{ HRD } & \multirow{5}{*}{$\begin{array}{l}\text { Human resource } \\
\text { development }\end{array}$} & Collective initiatives & \multirow{5}{*}{$\begin{array}{l}\text { Sambrook and } \\
\text { Stewart, } 2000\end{array}$} & HRD1 \\
\hline & & Available resources & & HRD2 \\
\hline & & Supporting systems & & HRD3 \\
\hline & & Quality of HRD staff & & HRD4 \\
\hline & & Career path & & HRD5 \\
\hline \multirow{5}{*}{ WORK } & \multirow{5}{*}{$\begin{array}{l}\text { Organization of } \\
\text { work }\end{array}$} & Work pressure & \multirow{5}{*}{$\begin{array}{l}\text { Sambrook and } \\
\text { Stewart, } 2000\end{array}$} & WORK1 \\
\hline & & Level of workload & & WORK2 \\
\hline & & Level of responsibility on the manager & & WORK3 \\
\hline & & Work complexity & & WORK4 \\
\hline & & Required creativity in work & & WORK5 \\
\hline \multirow{3}{*}{ LEARN } & \multirow{3}{*}{ Lifelong learning* } & Formal learning & \multirow{3}{*}{ Demirel, 2009} & LEARN1 \\
\hline & & Informal learning & & LEARN2 \\
\hline & & Non-formal learning & & LEARN3 \\
\hline
\end{tabular}




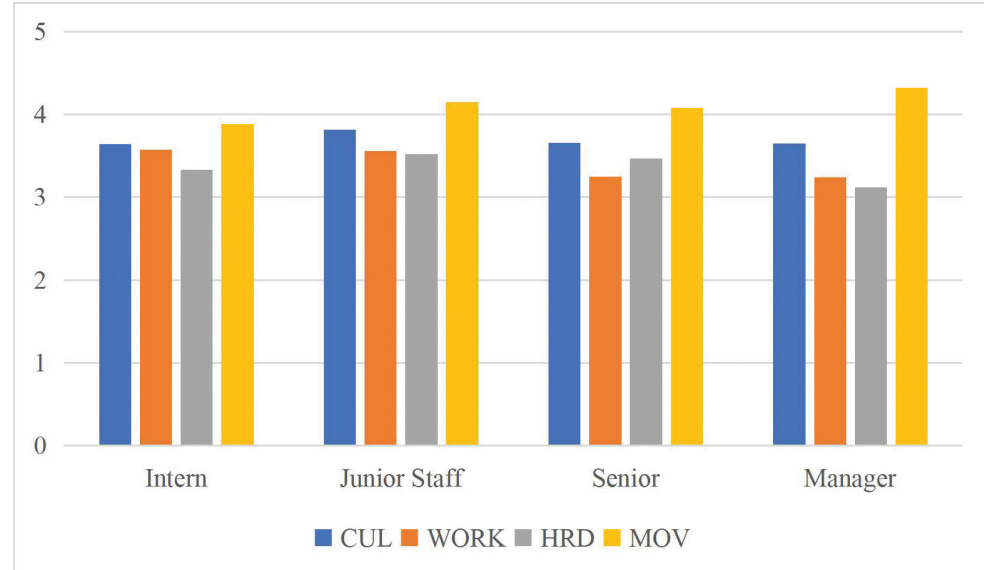

Figure 1: Factors affecting lifelong learning by position

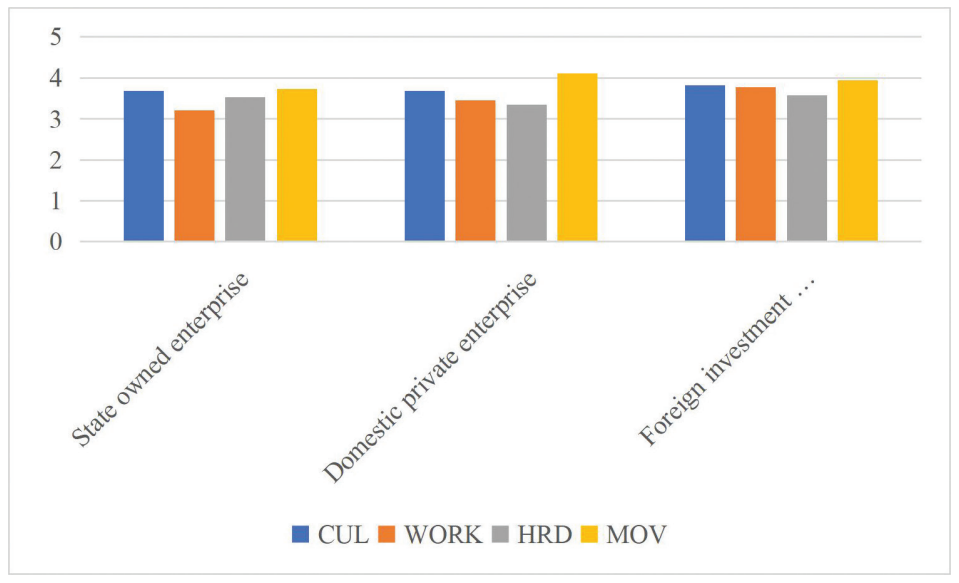

Figure 2: Factors affecting lifelong learning by Business Sector

In contrast, staffs engaging in the other two types of business sectors consider human resource development as the factor least influential in lifelong learning. However, one should be aware that the exposure of individuals to the development activities from the human resources department is still limited. Therefore, it can be said that there are not many initiatives on learning development from domestic private enterprises and foreign investment enterprises.

\subsection{Regression Analysis}

\subsubsection{Measuring Reliability}

We put four independent variables into Cronbach's Alpha test to investigate if the data is internally consistent enough to be influenced by the lifelong learning ability. Lifelong learning ability thereby is measured as in the category of dependent variable also. Subsequently, the Cronbach's Alpha coefficient values for each independent and dependent variable are higher than 0.7 , so it has good internal consistency and satisfies the reliability required as well. However, it should be noticed that some variables are removed due to the insufficient value of the total correlation (lower than 0.3) and the excess in Cronbach's Alpha if Item Deleted is compared to the original Cronbach's Alpha value. Therefore, Table 2 illustrates the final list of variables that can be applied for further examinations.

\subsubsection{Analysis of Discovery Factor EFA}

The first analysis of the discovery factor as KMO and Bartlett's Test results in the $0.5 \leq \mathrm{KMO}=0.853 \leq 1$, so that factor analysis is accepted with the research data set. Moreover, Sig Bartlett's Test $=0.000<0.05$, so factor analysis is appropriate. By implementing Total Variance Explained analysis, it is recognized that Eigenvalue value $=1.04 \geq 1$, and we extract four factors that consist of the best-summarized information. Moreover, the total variance extracted equals $74.069 \geq 50 \%$, showing that the EFA model 
is suitable. Thus, four extracted factors were condensed to $74.069 \%$ of the observed variables.

Furthermore, from rotated component matrix analysis, it is concluded that there is a list of variables that violate the distinctiveness in the component matrix with load factors. Therefore, the variables WORK1, HRD3, MOV1, MOV2, MOV3, MOV4 are eliminated. Subsequently, the research model equation is LEARN $=\mathrm{f}(\mathrm{HRD}, \mathrm{CUL}, \mathrm{WORK})$. The remaining variables are listed in Table 3.

\subsubsection{Regression Analysis}

Retrieved from Table 4, the Adjusted R-squared as 0.9010 is genuinely good in this study because of the rule that the value of adjusted R-squared value should be from 0.5 to 1 . Therefore, the change of lifelong learning variables is explained by $90.10 \%$ of the change in independent variables, including demographic variables. Moreover, the regression model is statistically significant as $\mathrm{F}(10,321)=302.16, \mathrm{p}=$ .0000 , which points to a considerably high number that $\beta_{1}$, $\beta_{2}, \beta_{3}, \beta_{4}, \beta_{5}, \beta_{6}, \beta_{7}, \beta_{8}, \beta_{9}$ and $\beta_{10}$ do not know jointly equal to 0 . So that, the examined model can statistically significantly forecast the lifelong learning-dependent variable. Nevertheless, after consideration to retain the variables, which satisfy the requirement on P-value as lower than 0.05 , the variables which are not significant are WORK, Gender, Foreign investment enterprise, State-owned enterprise, Age, Qualification, and Position.

Table 3: Variables after analysis of the discovery factor

\begin{tabular}{|l|c|c|}
\hline Variable & Model & Deleted Item \\
\hline Organization's culture & CUL1, CUL2, CUL3 & N/A \\
\hline Human Resource Development & HRD1, HRD2, HRD3, HRD5 & Quality of HRD staff \\
\hline Organization of work & WORK2, WORK3, WORK5 & $\begin{array}{c}\text { Work pressure and } \\
\text { Work complexity }\end{array}$ \\
\hline Lifelong learning & LEARN1, LEARN2 & Non-formal learning \\
\hline
\end{tabular}

Table 4: Regression analysis

\begin{tabular}{|c|c|c|c|c|c|c|}
\hline \multirow{2}{*}{ Source } & \multirow{2}{*}{ ss } & \multirow{2}{*}{ df } & \multirow{2}{*}{ MS } & \multicolumn{2}{|c|}{ Number of obs } & 332 \\
\hline & & & & \multicolumn{2}{|c|}{$F(10,321)$} & 302.16 \\
\hline Model & 311.030049 & 10 & 31.1030049 & \multicolumn{2}{|c|}{ Prob > F } & 0.0000 \\
\hline Residual & 33.0422399 & 321 & .102935327 & \multicolumn{2}{|c|}{ R-squared } & 0.9040 \\
\hline \multirow{2}{*}{ Total } & \multirow{2}{*}{344.072289} & \multirow{2}{*}{331} & \multirow{2}{*}{1.03949332} & \multicolumn{2}{|c|}{ Adj R-squared } & 0.9010 \\
\hline & & & & \multicolumn{2}{|c|}{ Root MSE } & .32084 \\
\hline LEARN & Coef. & Std. Err. & $\mathrm{t}$ & $P>|t|$ & \multicolumn{2}{|c|}{ [95\% Conf. Interval] } \\
\hline CUL & .6869143 & .0363522 & 18.90 & 0.000 & .6153955 & .758433 \\
\hline HRD & .4660865 & .0330942 & 14.08 & 0.000 & .4009777 & .5311954 \\
\hline WORK & -.0154709 & .0337705 & -0.46 & 0.647 & -.0819103 & .0509685 \\
\hline Gender & .0274805 & .0359886 & 0.76 & 0.446 & -.0433228 & .0982838 \\
\hline FORE & -.0932251 & .0697365 & -1.34 & 0.182 & -.2304233 & .0439731 \\
\hline GOVE & .0496092 & .0840774 & 0.59 & 0.556 & -.1158031 & .2150216 \\
\hline FRI & .195048 & .0614111 & 3.18 & 0.002 & .0742289 & .315867 \\
\hline Age & .0179253 & .0183197 & 0.98 & 0.329 & -.0181166 & .0539672 \\
\hline Qualification & .039537 & .0874289 & 0.45 & 0.651 & -.132469 & .211543 \\
\hline Position & -.0231197 & .0231687 & -1.00 & 0.319 & -.0687013 & .0224619 \\
\hline _cons & -.8992869 & .4260747 & -2.11 & 0.036 & -1.737539 & -.0610353 \\
\hline
\end{tabular}


For the organizational culture, because of the large coefficient value as $0.687(\mathrm{Sig}=0)$ and a tremendous t-test value of 18.9 , this independent variable is considered to be the top variable that influences lifelong learning. Moreover, that the value is positive expresses the 'plus' in the regression equation, as well as the positive relationship; the higher organizational culture level that supports employees, the higher their productive and lifelong learning is boosted. It is necessary that by investing in the culture, from the perspective of an organization, the organization itself can have the ability to strive and successfully face the competitors in the industry because of the combination of sharing work experience and learning-oriented culture. As the learning-oriented culture boosts the initiative and the proactive characteristics of employees, so that they take it as an opportunity to develop, the sharing of work experience to consolidate account for the tremendous proportion of synchronizing the knowledge that employees have gained.

The next factor that is shown to affect lifelong learning is human resource development with the P-value as 0 , which is below 0.05 . However, the effect of human resource development is lower than the effect of organizational culture as evidenced by the lower coefficient value. With a significant t-test value as 14.08 and a coefficient value of 0.466 , with $95 \%$ of the statistical significance, human resource development is subsequently claimed to have a positive influence on lifelong learning. Therefore, the growth in individual lifelong learning is determined by the increased effort generated by development activities from the human resources department. As in the digital transformation stage, the organization's culture and human resource development jointly work together with the purpose of the successful business. Exploratory factor analysis has recommended that the human resources department should have collective initiatives, so that employees can prepare their mindset to proactively learning with available resources and supporting the employee system. Moreover, a career path for each employee should be established to ensure that the employees' goal of learning and career development is comparable to the vision of the enterprise.

Three types of business sectors - domestic private enterprises, state-owned enterprises, and foreign investment enterprises - have shown the more positive figures. With a significant t-test value as 3.18 and a coefficient value of 0.002 , the only variable, which composes the enhancement of individual lifelong learning capability is the domestic private sector of business. It is understandable that in Vietnam, the prerequisite to participate in both types of enterprise is fairly high that candidates are required to have previous experience, or they need to be outstanding, among others, in order to be chosen. Consequently, young people often decide to join a domestic firm because there is a greater numbers of them these days.

However, other variables that are not statistically significant should be rejected. Firstly, the case that nature of work factor (coefficient value $=-0.15, \mathrm{P}$-value $=0.647>0.05$ ) is eliminated is relatively understandable. The elimination can be explained by the practical angle, which emphasizes the characteristics that directly affect the result of work, such as the improvement of effectiveness in working or the required commitment in work. Next, demographic variables such as gender, age, qualification, and position are rejected as insufficient in meeting the requirements. Vietnamese people have already attained an appropriate sense of learning and how to learn well than to the good education and training. Moreover, the Vietnam labor market becomes more and more accepting participants who concentrate on the required skills, the culture of enterprises, or the sharing of knowledge rather than the position and personal qualification.

In summary, the actual signals from the hypotheses for independent variables are mostly positive. Moreover, the high proportion of variables is rejected from the model because of they are unsatisfactory. There are only three variables that satisfy the prerequisites - organizational culture, human resource development, and the domestic private type of business sector. However, out of the three variables, organizational culture is the most effective factor that contributes to the lifelong learning ability of an individual. The next, but with lower impact factor is human resource development. However, the t-test value of this variable is also considerably high, so that it has strong statistical significance at $95 \%$. The last point is that the independent factor of domestic private enterprises has the P-value of 0.002 , which is much lower than 0.05 as a requirement and the coefficient value as 0.195 . The factor of domestic private enterprises undoubtedly ranks third in the context of factors influencing lifelong learning.

\section{Conclusions}

In conclusion, the research has investigated the lifelong learning variable as well as provided a summary of factors that are influencing the dependent variable. Subsequently, the questionnaire developed as per the research by Selvi (2009) and Sambrook and Stewart (2000) has contributed to the descriptive analysis. Although this analysis illustrates the high rates of motivation and organizational culture, which are assumed by observations to influence their lifelong learning, correlation analysis and coefficient testing show the results that only organizational culture is confirmed to be the influencing factor. Other independent factors are human resource development and domestic private enterprise. 
This study seeks to contribute to the scholarship on the subject in the context of Vietnam. In particular, the third stage in life for people who are 25 years old and older upper is directly addressed by this study. This group of people prefers to enhance their knowledge in working place via informal learning. Furthermore, as it has been mentioned, sociocultural factors receive a great impact from lifelong learning so policies should be applied to all citizens (Wang, 2008). Given the Vietnamese Prime Minister's project of building a learning society over the period from 2012 to 2020, the findings from this study are timely in offering a detailed contribution to accompany the government strategies of as well as reviewing previous lifelong learning studies.

This study covers many issues surrounding lifelong learning, so the individuals as employees in all three types of enterprises should take advantage of it for their long-term development. Subsequently, the human resource department should regard lifelong learning as a significant factor that affects, not only the individual itself, but also the time, the ability, and the effectiveness of the success of their company. Moreover, further studies can also sharpen the evidence with the analysis related to learning. Larger scale research should be considered; education program and teaching capability of educational institutions and even the Ministry of Education and Training could consider this study as introducing novel elements into their mindset. Furthermore, the decision on new and updated strategies for future teaching and training projects referring to lifelong learning is also encouraged by this research paper.

\section{References}

Ahlgren, L., \& Engel, L. C. (2011). Lifelong learning through SMEs: exploring workplace learning in the UK. Journal of Workplace Learning, 23(5), 331-348.

Altuwaijri, B. M., \& Kalyanaraman, L. (2020). CEO EducationPerformance Relationship: Evidence from Saudi Arabia. Journal of Asian Finance, Economics and Business, 7(8), 259286. https://doi.org/10.13106/jafeb.2020.vol7.no8.259

Anderson, J. R. (1995). Learning and Memory: An Integrated Approach. Hoboken, NJ: John Wiley and Sons Inc.

Chang, D.-F., Wu, M.-L., \& Lin, S.-P. (2012). Adults engaged in lifelong learning in Taiwan: Analysis by gender and socioeconomic status. Australian Journal of Adult Learning, 52(2), 310-335.

Chłoń-Domińczak, A., \& Lis, M. (2013). Does gender matter for lifelong learning activity (Vol. 16). NEUJOBS Working Paper. Collins, M. A., \& Amabile, T. M. (1999). Motivation and creativity. In: R. J. Sternberg (Ed.), Handbook of creativity (pp. 297-312). Cambridge University Press.

Demirel, M. (2009). Implications of lifelong learning on educational institutions. Cypriot Journal of Educational Sciences, 4, 199-211.
Demirel, M. (2009a). Lifelong learning and schools in the twentyfirst century. Procedia Social and Behavioral Sciences, 1, 1709-1716.

European Centre for the Development of Vocational Training. (2014). Terminology of European education and training policy. Luxembourg: Publications Office of the European Union.

Fouarge, D., Schils, T., \& Grip, A. D. (2013). Why do low-educated workers invest less in further training? Applied Economics, 45(18), 2587-2601.

General Statistics Office of Viet Nam. (2015 - 2018). Unemployment rate of labour force at working age. General Statistics Office of Viet Nam.

General Statistics Office of Viet Nam. (2018). Labour force at 15 years of age and above by age group. Retrieved from https:// www.gso.gov.vn/default_en.aspx?tabid $=774$

International Labour Organization. (2020). World Employment and Social Outlook: Trends 2020. International Labour Organization.

Kirby, J. R., Knapper, C., Lamon, P., \& Egnatoff, W. J. (2010). Development of a scale to measure lifelong learning. International Journal of Lifelong Education, 29(3), 291-302.

Laal, M. (2011). Impact of Technology on lifelong learning. Procedia - Social and Behavioral Sciences, 28, 439-443.

Laal, M. (2011). Lifelong learning: What does it mean? ProcediaSocial and Behavioral Sciences, 28, 470-474.

Minitry of Education and Training. (2019). She is always willing to study in practice. Ha Noi, Vienam: Minitry of Education and Training.

Nguyen, N. B. (2015). Lively living and Phuong diligently learns from the group of the workers in the garden. Labor Science and $\mathrm{XaHoi}, 31-34$.

Park, K. H. (2017). Education, globalization, and income inequality in Asia. ADBI Working Paper No. 732.

Rahman, S., Mia, M., Ahmed, F., Thongrak, S., \& Kiatpathomchai, S. (2020). Assessing Students' Satisfaction in Public Universities in Bangladesh: An Empirical Study. Journal of Asian Finance, Economics and Business, 7(8), 323-332. https://doi.org/10.13106/jafeb.2020.vol7.no8.323

Sagna, O. (2005). Lifelong learning in the African context: A practical example from Senegal. In C. McIntosh, \& Z. Varoglu, Lifelong Learning \& Distance Higher Education (pp. 51-61). Commonwealth of Learning / UNESCO Publishing.

Sambrook, S., \& Stewart, J. (2000). Factors influencing learning in European learning oriented organisations: issues for management. Journal of European Industrial Training, 24(2/3/4), 209-219.

Samphantharak, K. (2019). Economic Development of Southeast Asia: Country Experience. Available at SSRN 3329062.

Sanders, J. M., Damen, M. A., \& Dam, K. V. (2014). Are positive learning experiences levers for lifelong learning among low educated workers? Evidence-based HRM, 3(3), 244-257. 
Selvi, K. (2009). Lifelong Learning and Self-Actualization. Memory in the Ontopoesis of Life, 102, 51-66.

Senge, P. M. (1990). The Fifth Discipline: The Art \& Practice of The Learning Organization. London, UK: Lecturing Business.

Sharples, M. (2000). The design of personal mobile technologies for lifelong learning. Computers \& Education, 34(3-4), 177193.

Van der Stelt, H., \& De Voogd-Hamelink, M. (2009). Trend Report: Supply of Labour in 2009.

Stewart, J. (1992). Towards a model of HRD. Training and Development, 11(4), 26-29.

Terziev, V. (2019). Lifelong learning: the new educational paradigm for sustainable development. 6th International Conference on Education and Social Sciences (pp. 604-620).
Dubai, UAE: International Organization Center of Academic Research.

Uzunboylu, H., \& Hürsen, Ç. (2011). Lifelong learning competence scale (LLLCS): The study of validity and reliability. Hacettepe Üniversitesi Eğitim Fakültesi Dergisi, 41(41), 449-460.

Vu, H. M. (2020). A Review of Dynamic Capabilities, Innovation Capabilities, Entrepreneurial Capabilities and Their Consequences. Journal of Asian Finance, Economics and Business, 7(8), 485-494. https://doi.org/10.13106/jafeb.2020. vol7.no8.485

Wang, C.-Y. (2008). Enhancing the interactive relationship between lifelong learning and social changes to carry out a learning society in Taiwan. International Journal of Lifelong Education, 27(5), 535-542. 